\title{
Undergraduate medical education in New Brunswick
}

$\mathrm{I}^{\mathrm{n}}$ the Fall of 2005, the New Brunswick government, under the leadership of Bernard Lord and his Progressive Conservative caucus, began discussions with the Faculty of Medicine at both Dalhousie and Memorial Universities to determine the feasibility of developing a four-year Anglophone medical education program in the province. The two schools were originally working together to create a proposal for the program, but Memorial University dropped out of these discussions in March of 2006 for financial and logistical reasons. Since that time, the Faculty of Medicine at Dalhousie has continued working towards the development of a New Brunswick-based program. A recent announcement by the current Liberal provincial government, led by Shawn Graham, sets the target opening date of a new Dalhousie Medical School campus in New Brunswick to the Fall of 2009.

The intention of the New Brunswick government to proceed to final negotiations with the Faculty of Medicine at Dalhousie University was officially announced in June, 2007 by the provincial Minister of Health, Michael Murphy, and Minister of Post-Secondary Education, Training, and Labour, Dr. Edward Doherty. The proposed program, called the Dalhousie-New Brunswick Medical Education Program (DNB-MEP), is to be based at the University of New Brunswick in Saint John (UNBSJ), with clerkship rotations most likely occurring in major Anglophone centers in the province, including Moncton South-East, Fredericton, and Miramichi. Multiple target opening dates for the program have been set by the New Brunswick government since discussions with Dalhousie Medical School commenced. The original goal of the Lord government was to begin training students in Saint John in the Fall of 2007. Premier Graham later proposed that the opening date be delayed until 2008. The latest announcement sets the Fall of 2008 as a target date for the completion of negotiations, so that classes may begin in the Fall of 2009. However, Dr. Harold Cook, Dean of Medicine at Dalhousie University, has suggested that the proposed start date may change again; he has indicated that following the completion of negotiations, two years may be required to overcome logistical challenges before the program could commence. Dr. Cook asserts that this additional time may be required to establish infrastructure, recruit faculty, and restructure the undergraduate medicine program such that it may train and support 30 medical students per class in Saint John. For example, the New Brunswick government would require time to hire 27 physicians for whom teaching as part of the DNB-MEP would occupy one-third of their vocation. The provision of anatomy instruction within the DNB-MEP could constitute a unique logistical challenge since Saint John does not currently have a cadaver laboratory. During the first years of a new program, students may complete two months of study in anatomy at the main Dalhousie Medical School campus in Halifax until a cadaver laboratory is established in Saint John.

Providing a high quality medical education is the top priority of the Faculty of Medicine. Dr. Cook insists that the proposed program will be of the same calibre as its Halifax-based counterpart. Mike Ripley, Past President of the Dalhousie Medical Student Society (DMSS), echoed this sentiment. He maintains that all Dalhousie medical students must receive the same level of education and student services, whether based in Halifax or Saint John. In order to best serve future Dalhousie medical students at both sites, the DMSS plans to mirror successful initiatives of the medical student societies at the University of British Columbia and the Northern Ontario School of Medicine; both of these universities have established medical training programs that operate from more than one campus.

In addition to information pertaining to the quality of the proposed program and its supporting services, prospective medical students will likely take great interest in what becomes of the medical school seats that are already preferentially offered to New Brunswick residents. Dalhousie University currently admits up to 20 New Brunswick residents into its undergraduate medicine program each year, while Memorial University admits an additional 10. Now that Dalhousie will most likely expand its undergraduate medicine program to include the DNB-MEP, the future of the seats that are, at present, preferentially offered to New Brunswick residents has become unclear. The Faculty of Medicine at Dalhousie has not yet made a final decision regarding how seats at its Halifax campus, that are currently assigned to New Brunswick students, will be allocated following implementation of the DNB-MEP. However, it is expected that the total number of medical students admitted annually at Dalhousie will increase to approximately 110 to 120 students, including the 30 students to be admitted into the DNB-MEP. In recognition of the benefit of rural practice exposure that students receive at Memorial University, the New Brunswick Medical Society wants the 10 seats offered to New Brunswick students at Memorial University to be maintained and funded by the New 
Brunswick government. However, funding undergraduate medicine programs is costly. The New Brunswick government is expected to compensate Dalhousie University for providing the new program at a rate similar to the amount that is paid by the Nova Scotia government for each of its students, which is approximately $\$ 55,000$ per year. This means that once the DNB-MEP has a full complement of students, the New Brunswick government would contribute to its funding at an amount of approximately $\$ 7$ million per year. Additional funding is expected to be provided initially for infrastructure.

An agreement between Dalhousie University and the province of New Brunswick is expected to be finalized in the months ahead. Almost two years have passed since the Lord government announced its vision for an Anglophone undergraduate medicine program in the province; it indeed appears that sufficient time is being taken to ensure that the program is established in a manner that will allow New Brunswick students to continue to receive a top quality education.

\section{John Paul Harmon}

Class of 2009, Faculty of Medicine, Dalhousie University

\section{Cape Breton Island} Great People, Great Place, Great Life

The Cape Breton District Health Authority requires physicians for:

- Pediatrics

- Neurology

- Family Medicine/Emergency (New Waterford)

- General Surgery (Inverness)

- Anesthesia

- Infectious Diseases

Through regional, community and rural hospitals, Continuing Care, Mental Health Services, Addiction Services, Public Health Services and the Cape Breton Cancer Centre, the District serves more than 130,000 people. Cape Breton's unique beauty, diverse culture and year-round recreational opportunities make the Island a vibrant place to practice and play.

All candidates must be certified by the Royal College of Physicians and Surgeons and be eligible for licensure in the province of Nova Scotia.

Inquiries and applications to:

Dr. M.A. Naqvi, Medical Director

Cape Breton District Health Authority

1482 George Street

Sydney, Nova Scotia B1P 1P3

Fax: (902) 567-7921

E-mail: naqvim@cbdha.nshealth.ca

टํ. Cape Breton District

HEALTH AUTHORITY

Making Healthier Choices Together
* Relaxed Lifestyle

* Affordable Homes

* www.cbdha.nshealth.ca

* www.cbisland.com

www.capebretonisland.com
* Nurturing Communities 